\title{
Design Study of a Medical Device
}

\author{
Burcu Taşkın, Nuri Başoğlu \\ Izmir Institute of Technology, Department of Industrial Design, Urla, Izmir, Turkey
}

\begin{abstract}
For the new product design in the medical industry, the designer's role is to identify requirements of product by focusing on the target need, demand and market supply. This research aims to explore the main problems of existing crutches in the medical industry with two phases; to identify the crutch design requirements by research and to define market position involving financial analysis with three economic scenarios. Therefore, the study based on a research with reutilize multiple techniques for walking aid design requirements through needs and demands, aims to discuss the collected data from different perspectives of medical experts, medical store owners and crutch users to create design criteria.

In conclusion, the study claims that the crutches should be designed with rich interaction, integration form and function. Besides, the economical scenarios are planned to create the crutch to be considered accessible, feasible for users and cost/price benefit for stakeholders.

The product concept was constructed considering the ergonomics, economics and medical issues to define requirements of the new crutch idea for temporary users. Therefore, the new crutch design specifications aim to alternate in terms of body-raise aid, stair ascent, arm-elbow support and self-standing functions.
\end{abstract}

\section{INTRODUCTION}

Mobility is an important issue in health case for the modern people. Medical devices such as crutches and walking aids are recommendable to avoid provisional disablement. The user perspective and medical expert opinion, which is about crutches being the only option, should be considered significantly. Besides, the market supplies the cheapest solution for mobilization issue. Nonetheless the existing products are not efficient and considered enough for after usage problems and usage problems.

The walking aid is highly related with user for healing the users physical problem. To demonstrate, the product can work as a body part. Thus, the integration form through identifying the target profile is a major issue that the research concerning. The scope narrowed as walking aid for temporary user. The research explores the user problems and after use problems while using walking aid.

On the other hand there is a high competition in the market. Therefore seeking of innovation and creativity in new product development process becomes an essential necessity for surviving in the changing marketplace [1]. However, the process of medical device design is difficult and complex that requires collaborative work and knowledge transfer between medical and engineering experts. In this context, the medical device design is a very specific area that includes complex procedures, various users, human factors and science [2]. The research focuses on exploring the existing crutches in the market to identify features of product regarding temporary user needs. In other words, the aim is to explore the main problems of existing crutches in the market with two phases; identifying the crutch design requirements by research and defining market position involving pre-financial analysis.

To conclude, we analyzed needs and demands of individuals on walking aids as medical devices for temporary crutch users. The study aims to develop guidelines for a new crutch design providing the user and the market needs by benefiting from outcomes of the research.

\section{LITERATURE REVIEW}

A. Creativity, Innovation, Design and New Product Development in Medical Device

Creativity and innovation are fundamental elements to develop new product concepts in engineering and design context. In order to understand the importance of these concepts and their interrelation, it is necessary to describe them briefly. Creativity is a result of idea generation process to form fresh and useful concepts. Innovation proposes the transformation of ideas into new products and services. Therefore, creativity represents the trigger of the entire innovation process. In the context of innovation, creativity results are applied to develop new products and services [1].

Previous researches underline the importance of design for success of the new product development (NPD). Most of the design literature points the efficiency and economic value of design in NPD process. It is mentioned that design driven NPD provides competitive advantage, evolves technical performance and reduces production costs. Besides, design orientation in NPD is an effective innovation process that pushes and moves business forward [3]. In addition, there are some internal factors within firms that directly create the competitiveness during innovation and NPD process. Applying of new technologies, investing on research and development activities are the most significant internal factors that increase the competitive advantage [4].

In the World Medical Association Declaration of Helsinki in 2000, thirty-two ethical statements were developed to guide human subject involved medical researches. According to the basic principles for all medical research "Medical research involving human subjects must conform to generally scientific knowledge of the scientific literature, other relevant source of information, and on adequate laboratory and, where appropriate, animal experimentation" [5]. Therefore, 
medical device design is a hard and challenging process that requires effective knowledge, practice and method management between medical, engineering and design experts during the medical design innovation process [2].

According to the medical device development literature, users' perspective has a great importance to analyze and improve user needs. Their involvement into the product development process is required to point out potential problems and deficiencies of existing medical devices. In addition, engagement with users has benefits on medical device development and evaluation through innovation, creativity and technology. The involvement of the user has the same amount of importance at each level and stage of the NPD process. However, their involvement has a crucial role during the idea generation phase rather than the further phases such as prototyping and/or testing [6].

Smaller medical device companies are trying to increase their market share via their better pricing and innovative business rather than searching for significant innovations in the product itself, since the stores are mostly saturated with non-innovative products and there are not many product improvements left to do. This makes the market more competitive in terms of offering lowest price while maintaining the full functionality [7].

Additionally, the current literature underlines that both device users and clinicians involvement into the medical device development is crucial. Therefore, valid, safe and usable data collected from their feedbacks in terms of ergonomics and human factors have vital role to guide medical device design process [2].

\section{B. Walking Aids as Medical Devices}

Walking aids are supportive medical devices that are prescribed by medical experts to the patients. The needs for walking aids are various such as "normal ambulation is compromised by pain, impaired balance, weakness, or musculoskeletal abnormality following trauma, surgery, or incapacitating pathology" [8]. In this context, crutches are the most commonly suggested and preferred medical walking aid devices that propose physiological and psychological advantages to people with disabilities. Therefore, many people are using crutches that have different kinds of disabilities or injuries such as "amputees, paraplegics, people with broken bones, people with torn ligaments and many others" [9]. In addition, crutches provide walking aid to mechanical or neurological disability and reducing lower limb stress [10].

According to the biomechanical evaluation of crutch design literature, walking aids like crutches have been used for over 5,000 years besides without major changes on their functional properties and forms [10]. Mostly two basic types of crutches are prescribed that are axillary crutches and forearm crutches. Axillary crutches are also known as underarm crutches. They consist of handgrip and armpit support parts. This type of crutch is generally suggested for short-term usage to the temporary crutch users. Forearm crutches are also known as elbow crutches. They consist of handgrip like axillary crutches, but the top point ends at elbow height. This type of crutch is also suggested for shortterm usage to the temporary crutch users [11].

Consequently, the selection of the type of crutch depends on the patient's injury and body type. In this selection the most important factors are "user's balance, weight-bearing status, and upper limb and trunk strength" [10]. In addition to the crutch choice the education of efficient gait pattern is crucial for inexperienced crutch users to gain safe and comfortable walking aid mobility [10].

Current literature underlines that, axillary and forearm crutches have both advantages and disadvantages in terms of their fundamental characteristics and properties. Some sources state that, elbow crutches provide more energy expenditure than axillary crutches. Therefore they are more safe and comfortable. However, more energy and effort is needed for ambulation with elbow crutches than axillary crutches [11].

In previous researches some problems caused by current crutch designs are stated. They classified under three main categories that affect directly the human factors and ergonomics. First, the usage of existing crutches demands high-energy expenditure during crutch ambulation and gait [12]. Second, some arm, hand and wrist injuries that caused by repetitive loads on these body parts during ambulation [13]. Third, lack of standing and walking cause some blood circulation and bone growth problems [14].

\section{Competitors in The Market}

The medical industry is different from the other sectors in terms of economics and market competition. The investment is listed with respect to the importance of the health issues. Nonetheless, according to the World Bank reports, the total health expenditures per person had doubled between 1970 and 2001 in United States [15]. "In 2009, the United States spent $17.4 \%$ of GDP on health, 5 percentage points more than in the next two countries, the Netherlands and France (which allocated $12.0 \%$ and $11.8 \%$ of their GDP on health)"[16]. Besides Garde notes that, "Diagnostics are predicted to be the industry's top segment, achieving global sales of $\$ 54.5$ billion. Neurology devices are expected to grow the fastest, expanding by $6.1 \%$ annually while orthopedics will grow the slowest at 3.1\%." [17]. As a result, medical industry has slow technological adoption, especially in orthopedics, in contrast to other sectors [18]. Graph 1 shows that the market share of the orthopedic and fracture devices are in the second place that means the demand of the products are not less. Hence, the identified and unidentified challenges of changing marketplace will be subjected to healthcare industry in the upcoming years [18]. 


\section{Proceedings of PICMET '16: Technology Management for Social Innovation}

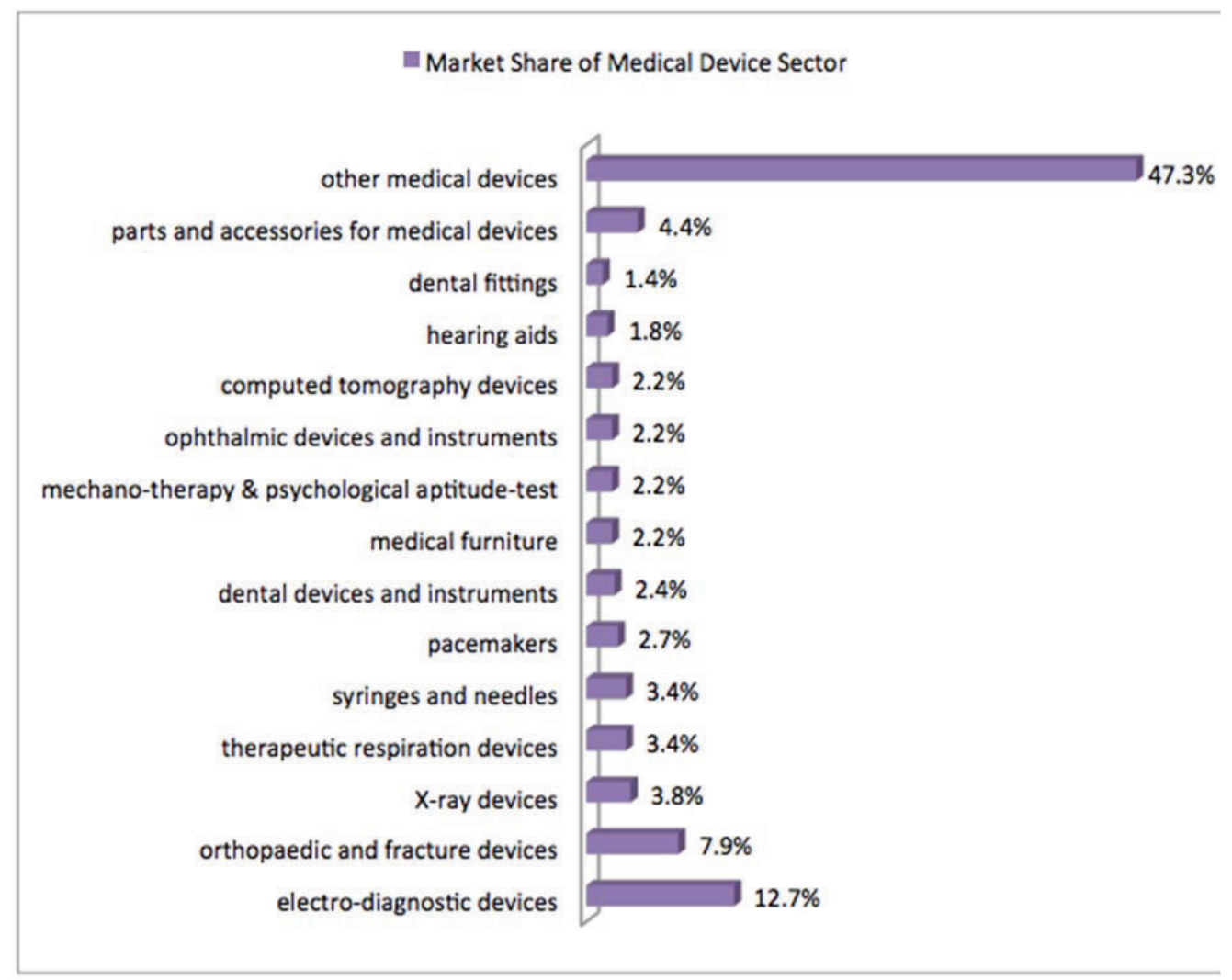

Graph 1: Global Market Share of Medical Devices [19]

The number of customers caring about the price/performance rate and accepting the redundancy of some features in return is increasing. In addition to the lack of features, quality and service times are also sacrificed to get the prices even lower since the highly innovative products are considered premium with high prices, thus making the cost reduction a must to create commodity perspective [20].

The design requirements should refer to the policies of world health organization (WHO). The WHO lists the examples of policies on medical devices [21] in their words as;

- Regulations of medical devices minimize risk to the population,

- Safe use and availability of medical devices improve health service delivery,

- Affordability of medical devices increases health service coverage,

- Telemedicine enhances patient centered care,

- Health technology assessment provides basis for priority setting and informed decision-making,

- Needs assessment helps in the rational allocation of resources, and

- Research and innovations respond to the needs of a particular health system and population.

On the other hand, sprained ankles and leg injuries are the most frequent health issues around the world. The use of crutches assists the walking with one leg to be mobile.
Besides, according to the report of 2013, the number of walker users is 1.8 million people and the number of crutch users is 566,000 per day in US [22].

\section{METHODOLOGY}

\section{A. Research Method}

In this study the major issue is to understand the needs and demands of various perspectives and identify the important requirements of the walking aid design. The study is formed as collaboration of academy and practice. The process of the study is based on reutilize multiple techniques to supplement core methods such as brainstorming, desk and field research, interview, user test, financial analysis and conceptual idea generation phase.

The study determines needs and demands analysis of users, medical experts and medical supply stores. The research questions following four factors to understand the issue comprehensively;

- Analysis of usage problems

- Analysis of post-usage problems

- Competitor analysis

- Financial analysis

The method of inquiry starts with understanding needs and demands analysis from different perspectives on walking aids to list design requirements. Therefore the research 
2016 Proceedings of PICMET '16: Technology Management for Social Innovation

TABLE 1

PHASES APPLIED IN THE RESEARCH

\begin{tabular}{|c|c|c|c|}
\hline Application & Phase & Participants & Outcomes \\
\hline \multirow[t]{5}{*}{ First } & Focus Group & $\begin{array}{l}10 \text { Participants (1 Material Engineers, } 2 \text { Mechanical } \\
\text { Engineers, } 6 \text { Industrial Designers, } 1 \text { City and Regional } \\
\text { Planner) }\end{array}$ & Target Identity, Existing Needs \\
\hline & Interview A & 2 Medical Supply Stores & $\begin{array}{l}\text { Bestselling Products, Common } \\
\text { Problems }\end{array}$ \\
\hline & Interview B & 4 Medical Experts & $\begin{array}{l}\text { Medical Problems After/ During } \\
\text { Usage }\end{array}$ \\
\hline & Online Survey & 5 Crutch Users & $\begin{array}{l}\text { Problem Definition on Existing } \\
\text { Products }\end{array}$ \\
\hline & User Test & $\begin{array}{l}3 \text { Participants (Testing Existing Forearm and Axillary } \\
\text { Crutches in The Market) }\end{array}$ & Practice based problems \\
\hline Second & $\begin{array}{l}\text { Analysis of } \\
\text { Competitors }\end{array}$ & 2 Experts (visual analysis, online user comments) & $\begin{array}{l}\text { Understanding alternative } \\
\text { solutions }\end{array}$ \\
\hline Third & $\begin{array}{l}\text { Pre-financial } \\
\text { Analysis }\end{array}$ & 3 Scenario Based Analysis & $\begin{array}{l}\text { Analyzing Internal Rate of Return } \\
\text { (IRR) for different scenarios. }\end{array}$ \\
\hline
\end{tabular}

continued with preparing survey through the elements of the problems and the demands of users.

The aim of the study is to define the problems of the walking aids, which should have superior body-product interaction. Therefore, the identification of user profile is important to identify the problems in medical device design. Besides the research is based on a user scenario that focuses on the target that has difficulties mostly in daily life while using the product. The target is chosen through focus group phase.

The Table 1 shows the phases of research according to participants and remarks of outcomes. Besides, three applications are conducted as explained below;

First application is to define the problem on existing crutches in the market. The data are collected through interviews from several sources like temporary crutch users, medical experts, and owners of medical supply stores. The main focus of the interviews is to generate a list of user needs.

Second application is to discuss and examine specifications and features of the alternative solutions in the market. Therefore, the product specifications that are pointed out through interviews and existing solutions are compared. Besides, we listed the parameters based on previous application for inspecting the potential of improvement on a new product.

Lastly, a pre-financial analysis as a pre-study is applied to explore accessibility issue on social and economical dynamics by analyzing IRR with three economic scenarios.

\section{First Application}

First application phases are focus group, interview A and $\mathrm{B}$, online survey and user test.
We conducted a focus group discussion that consists of ten participants with random sampling from Izmir Institute of Technology. The session announced and facilitated at the university. The age of the group was between 20-30 and their education levels were MSc or PhD candidates. Some of the participants were experienced crutch users unlike others. Therefore, some visual samples of the discussion subjects were shown and brief information about them was given before the session. All discussion was recorded and notes were taken. The main objective of the focus group session was to define the target identity, to generate a list of need analysis about medical devices and crutches in terms of design. In addition, outputs of the session were used to prepare interview questions that will be used in the next phase and we narrowed the scope in that session.

The next phases are interviews and survey. We conducted a semi-structured interview with random sampling for medical market to analyze the consumer preferences, product features and types. After exploring which types are suggested for our target users, we applied user test on axillary crutches and forearm crutches. In that phase, we recorded and took notes.

Through the interview with medical supply storeowner, we carried out semi-structured open-ended survey and unstructured interview on crutches with four medical experts; face-to-face, on phone and through Internet. At the same time semi-structured survey with open-ended questions were asked to users to define users' needs and problems on Internet. The snowball sampling was applied to reach the participants. Four male and one female answered the questions.

The last phase of first application is user test. We conducted user test to understand user-product interactions. This technique applied to observe and test the problems. Therefore, we applied a three participant-involved user test to 
search and define the problems of first time user experiences. The participants were at the age of 26, 29 inexperienced and at the age of 30 experienced crutch user. The interior of a medical supply store and the slope stone pavement in rainy weather were chosen as the user test settings. Scenario based analysis is applied in two settings. In the first setting the participants were asked to walk for five minutes on the marble floor of the medical supply store and sit down, stand up on a chair without any help. In the second setting, they were observed while walking on stone pavement in rainy weather for five minutes and climbing the stairs.

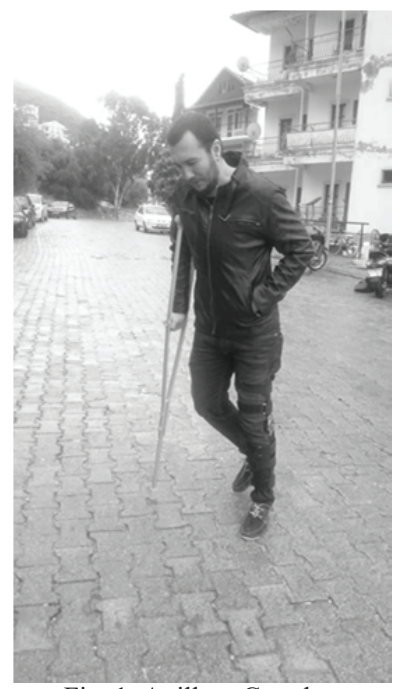

Fig. 1. Axillary Crutches User Test First Setting

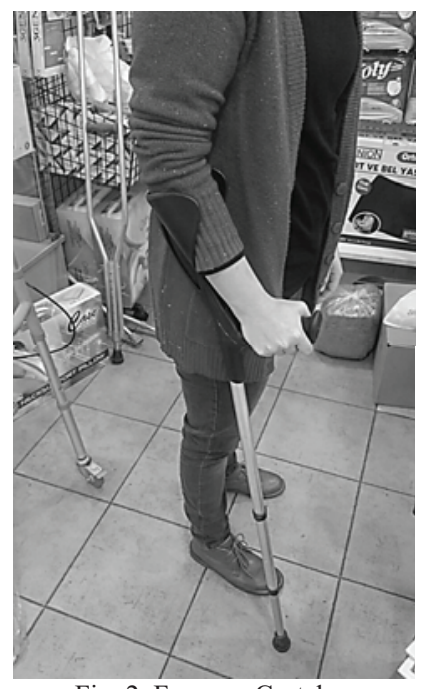

Fig. 2. Forearm Crutches User Test Second Setting

The most commonly preferred types of crutches, which are the axillary crutches, and the forearm crutches were tested and examined as shown in the Fig. 1 and Fig. 2. In that phase, the user test videos were recorded and the usage pictures were taken by digital camera, and interview dialogue was noted for documentation.

\section{Second Application}

Second application, which is the competitor analysis, is to understand the problems and solutions of existing potentials, for the new product design. The aim of this part is to understand the alternative solutions and to explore if the solution answers the problems in reference to interviews and survey.

We conducted a competitor analysis through a market research to understand market needs, market size and competition. In accordance, for a systematic data gathering and visualization we take the interviews' outcome as a parameter and graded the subject according to the online customer comments. We research both academic and nonacademic approaches discussed and compared.

The table 2 conducted to analyse the marketplace through the visual analysis and user experiences through the Internet. The proposed design requirements created to alternate and innovate the existing solutions.

\section{Third Application}

In this part, we conducted a pre-financial analysis to determine the market positioning in terms of product specifications. The financial analysis based on three scenarios to optimize user, market and social advantage.

The table of cost structure with three economic scenarios is conducted to define the investment return rate. The study is limited with three scenarios and all other alternatives could be effective for different cases.

\section{RESULTS}

\section{A. First Application Results}

According to the focus group discussion, the following major user needs were determined and were shown below;

- Self-standing function for the crutches

- Unaided sit down and stand up

- Hands free usage

- Easy storage

- Skid-proof

- Light weight

These results are fundamental for preparation of the survey questions. The participants as potential users observed that the listed problems initially affect the social life and daily life. In that phase the user profile was determined.

According to the focus group, mostly, people who are employed need to be mobile while they have lower extremity injury or surgery. Besides target, which is identified by focus group, does not have physical possibility to use crutches easily because of the leisured muscle conditions. To conclude, the research selects the temporary crutch users and 


\section{Proceedings of PICMET '16: Technology Management for Social Innovation}

working group by the age from 20 to 40 who have lower extremity injury or surgery as the target.

The medical supply store interview's critical results are listed below;

- Tripod crutches are not useful for walking, they generally hit to the user's leg

- Wooden crutches are heavy, therefore they have less demand

- Plastic crutches are washable and light, however they have short life cycle

As a brief summary, there are two types of crutches for temporary usage that are forearm crutches and armpit crutches in the medical market. The producers offer crutch handle variations in terms of material such as wood and plastic, and colour options with same form. In medical market, the price of a crutch is changing from 20 dollars to 500 dollars.

The study claims that the device should provide the user to stand up easier with the assistance of the crutches. Besides, they should allow hands-free usage to the user. On the other hand, study should focus on the storage functions of the crutches.

Survey results define the main problem of existing crutches as the lack of self-standing function. In other words, the problem occurs during the sitting time of user on a sitting unit. Second, because of the lack of body and weight support the user has difficulties of sitting and standing while using the crutches. Third, the user does not have opportunity to use his/her hands while standing with the crutches. The last problem is defined as the storage difficulty of the crutches while getting into a vehicle with them.

\section{Crutch Users' Perspective}

The participants varied between the ages of 20 to 30 . In total, five users of crutches had answered the online survey. In addition, $80 \%$ of the participants are male and $20 \%$ of them are female. According to the answers of the participants, $60 \%$ of them used forearm crutches and $40 \%$ of them used armpit crutches. The use period of the crutches changes from one month to two months for lower extremity injuries and surgeries.

The following answers of the participants are abstracted in below.

- The most wearing parts of crutches are;
o Handles
○ Tips
- Adjustment holes
- Elbow supports

- The usage problems on different surfaces are;

- Slippery surfaces

- Sloping surfaces

- The difficulties facing during sitting and standing are;

- The storage problem of crutches while sitting and the need of aid for standing
- The need of extra force for standing up

o The lack of different level or angled handles for standing up

- The height problem of the crutches that enforce the standing up

- The feelings of insecurity while standing

- The most common difficulties on usage of crutches are;

○ Self standing

- Unaided sit down and stand up

- Hands free usage

- Storage

○ Skid-proof

$\circ$ Weight and height adjustment

- Customization

- Durability and resistance

- Life cycle

Ergonomics

Affordability

Interrelation with public spaces, furniture, and etc.

- Other health problems occurred by crutch usage are;

- Hygiene problems

- Skin scratchiness

- Blisters in palm and armpit

- The requested extra functions and needs for crutches are;

- Handle should be closer to the ground

- Crutches may have tripod legs

- One crutch could be tripod, other could be standard

- Ease of store, hang, put etc.

- Foldable

- Comfortable, soft and ergonomic handle grips

- Changeable tips for hygiene

- Center of mass should be considered

- Hands free usage to carry bag, phone usage, drinking, exchange, etc.

\section{Medical Experts' Perspective}

According to the answers of the participants, crutches are supportive medical equipment, which provides mobility advantage to the patients. However, they may prevent arthritis in joints and some problems may occur on prolonged use of the crutches.

- The health problems may occur are;

- Joints get lazy

- Creates posture disorders

$\circ$ Damaging armpit and knee that the weight is carried by

- The additional comments and suggestions of medical experts are;

- Being soft does not always mean it is comfortable for handles or other parts of the crutches

- Height should be adjustable for handles and armpit parts

The existing crutches seem like cheap solution however the point of the medical experts explained the problems of posture and joints after usage. 


\section{Proceedings of PICMET '16: Technology Management for Social Innovation}

\section{User Test Results}

According to the user test experiences and results, illustrations were prepared to emphasize the user perspective. Body parts marked with colors are showing where the pressure and pain felt caused by crutches. Besides, the muscle groups marked with color are showing which are strained and sore. In Fig. 3 user experiences of axillary crutches and in Fig. 4 user experiences of forearm crutches are shown.
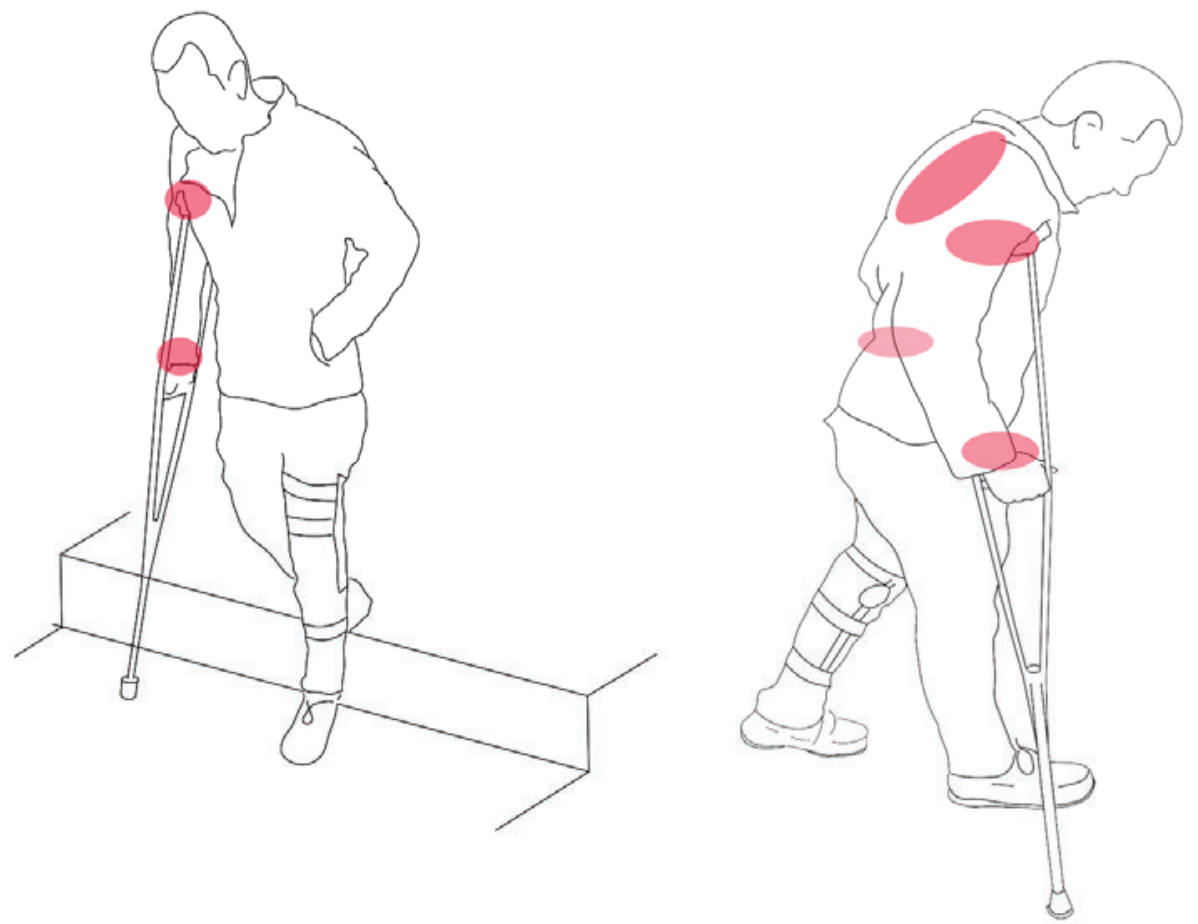

Fig. 3. Axillary Crutches User Experiences

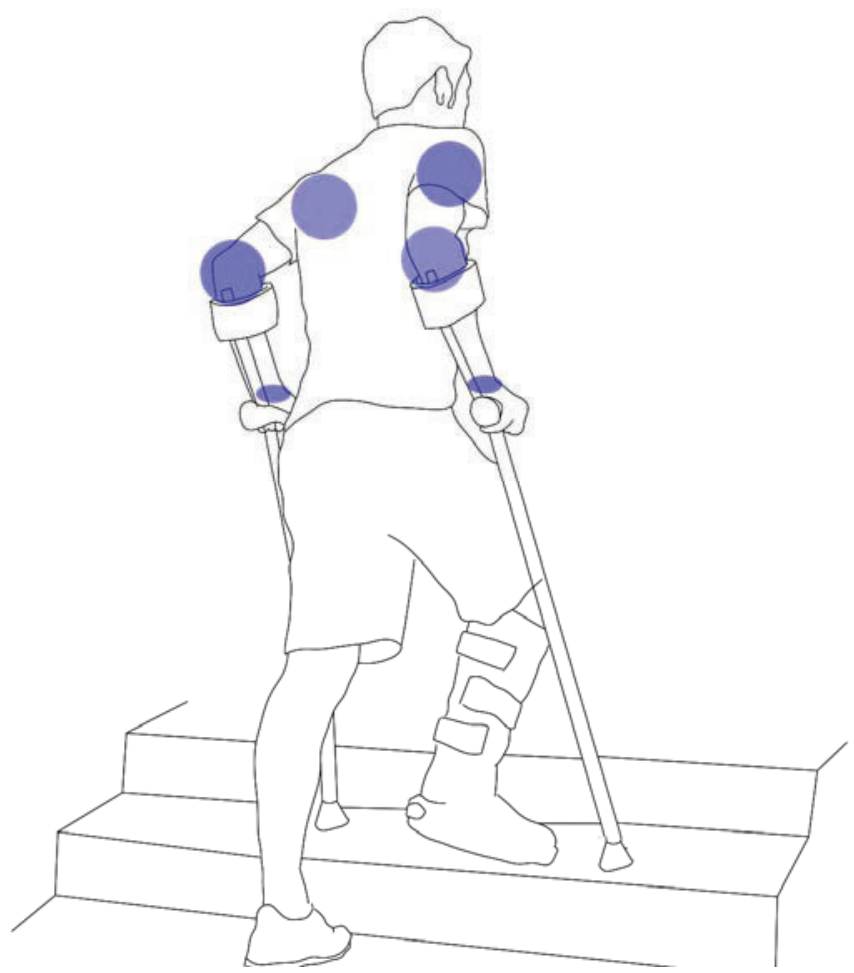

Fig. 4. Forearm Crutches User Experiences 


\section{Proceedings of PICMET '16: Technology Management for Social Innovation}

The test results are listed below;

- The crutches fall when the user left the elements behind the seat and sit

- Sitting down and standing up by the help of crutches are not easy

- There is no supportive element for the arm

- The pressure of weight on wrists cause pain

- Automobile does not have enough space to store the crutches

- Using hands for the daily activities such as opening the door, carrying a bag etc. while using the crutches is difficult

To conclude, the existing crutches fall short in hands-free usage, climbing stairs, walking on slippery surfaces and body-raise usage.

\section{B. Second Application Results}

The competitors analyzed in terms of elements of first application. The major aim of that part is to compare the products in the market. This phase is important to understand the existing or conceptual solutions.

The list of Table 2 is generated from the problem definitions regarding the needs and demands from the interviews and survey. The crutches are graded with the users' online comments and design principles by two experts. The data will be used for healing the problems and improving the existing solutions to propose crutch design requirements.

The products are selected through the innovative performance for inspiration. Each specification and performance is graded with $(*)$, which refers to being satisfactory or unsatisfactory. The important subjects are carried out to table to compare the products.
The list shows that the self-standing, body raise aid and storage advantage are the major potential subjects for the new design. In the context of that table the economic scenarios should be analyzed according to the devices' accessibility and affordability for everyone.

\section{Third Application Results}

The first scenario is created for the Turkish market. The demand is calculated as 22.000 people, in direct proportion to the US statistics [21]. In that scenario the cost/price balance is measured to compare with the existing crutches. The investment would be higher in the beginning and there is no expansion investment. The gross income is the lowest, because it could be the encouragement of government or a project with the collaboration between university and producer. The materials could be carbon fiber and aluminum with support of foundations or government. The unit cost calculated for the producers with minuend stakeholders' encouragement.

The second scenario starts with minimum investment and less demand with a high technology and higher price to increase the gross income. The materials in the product specifications below are preferred in this scenario. In this scenario the limited crutches could be in the market with higher price comparing with other scenarios. The demand will increase incoming years because of the advantage of the long-term life.

The third scenario is demonstrated with same investment as the first scenario with doubled cost and price. However the differences between the third and first scenarios are the expansion investment and demand as shown in Table 3. The materials are preferred as more aluminum less carbon fiber. 


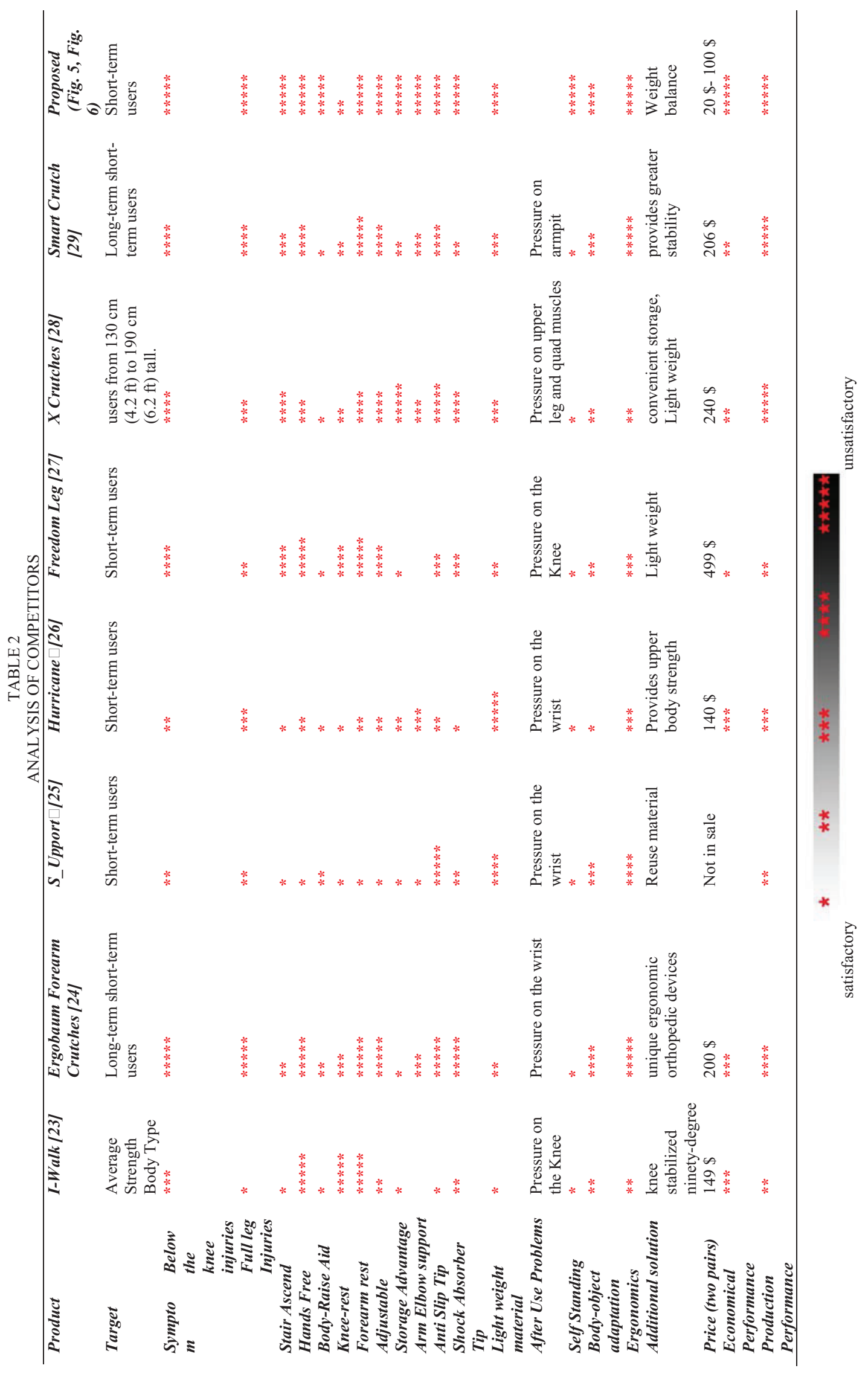


TABLE 3

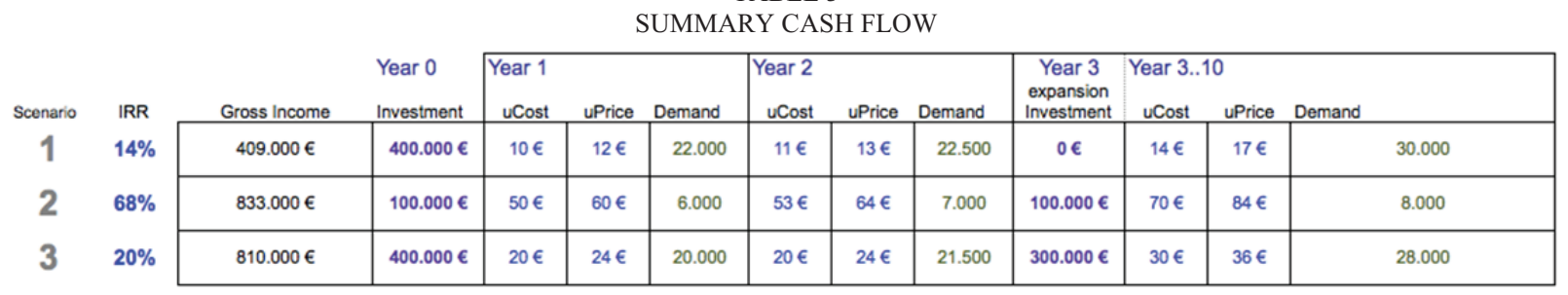

This sample pre-financial study is to understand the IRR with cost, price and demand. This application is an exploration on financial model for the companies to produce lower cost through initial design requirements for walking aids to optimize the design requirements.

\section{Draft Product Specifications and Discussions}

In this part, the product attributes and detailed specifications of the proposed new crutch design are mentioned accordance with the collected data during the research. The proposed new crutch design serves to the user needs collected through the research, which are body-raise aid, stair ascent, arm-elbow support and self-standing functions. In this context, the material, dimensional and functional characteristics of the new product are listed in the table 4.

The proposed new crutch design and its specifications are mentioned under four categories in the Table 4. Additionally, the draft design sketches of the proposed new crutch design are shown in Fig. 5 and Fig. 6. The draft design provides adjustable tube, which can be controlled by the rotational elbow support not only for unaided sit down and stand up, but also for stair ascent. The cushioned arm elbow support with silicone rubber grip adjusts the height of sticks with a basic control mechanism, which is arranged by up and down movement. In addition to that the adjustment of sticks enables storing of the walking aids. Besides wearable elbow strap helps hands-free usage. Hence, shock absorber silicone tip ensures walking on slippery surfaces and stony surfaces. Usage of lightweight materials as shown above enhances portability, durability of the devices, additionally it causes less fatigue while carrying and walking.

For the new product development after defining the design requirements through several researches, the designers propose the design as a prototype, which is tested with several user tests. In medical device design the same process is followed involving the economic scenarios. The medical devices should be standardized in reference to the reports of health organizations. The designers do not only deal with the material, the technology, and production techniques but also the economic issues, social issues and daily life issues.

TABLE 4

PRODUCT SPECIFICATIONS

\begin{tabular}{ll}
\hline SPECIFICATIONS & 1.0 to $1.5 \mathrm{~m}$ \\
Size & Forearm Crutch \\
Type & Carbon Fiber Reinforced Composite, Thermoplastic, \\
Material/s & Carbon Fiber Reinforced Polymer, Alluminium Alloy, \\
& Silicone Rubber \\
PARTS & YES (Adjustable \& Replaceable) \\
Handle/ Grip & YES (Cushioned \& Adjustable) \\
Arm-Elbow Support & YES (Adjustable) \\
Wearable Elbow Strap & YES (Graduable Silenced Tubling) \\
Crutch Tube & YES (360 Degree Rotation) \\
Crutch Tip & \\
& \\
FUNCTIONS & YES \\
Body-Raise Aid & YES \\
Stair Ascent & YES \\
Arm-Elbow Support & YES \\
Self-Standing & \\
ADDITIONAL FEATURES & YES \\
Foldable Body & YES \\
Adjustable Height & YES \\
Adjustable Angle Grip & YES \\
Schock Absorber Tip & YES \\
Silicone Grip & YES \\
Skidproof- Replaceable Tip & YES \\
Waterproof Material & YES \\
Cleanable Material & YES \\
Long Life Time &
\end{tabular}


The draft walking aid and its specifications are determined through the scenario based research and competitors analysis. Thus, these are not only the methods for producing the walking aid, however the time limitation for that research concludes the product in terms of requirements, which could be developed with different scenarios. The research is significant to bridge the design and medical sector in the context of economic, ergonomic and social issues.

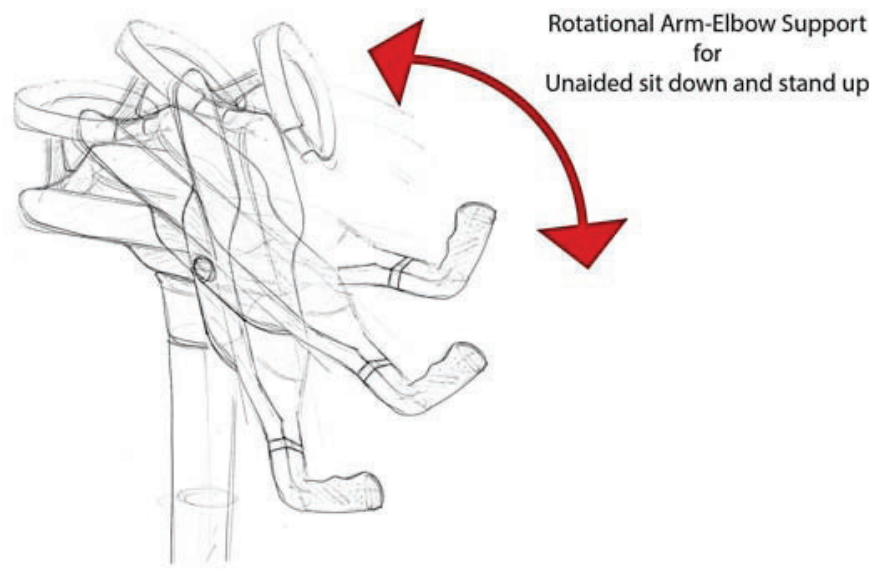

Fig. 5. New Crutch Design Details

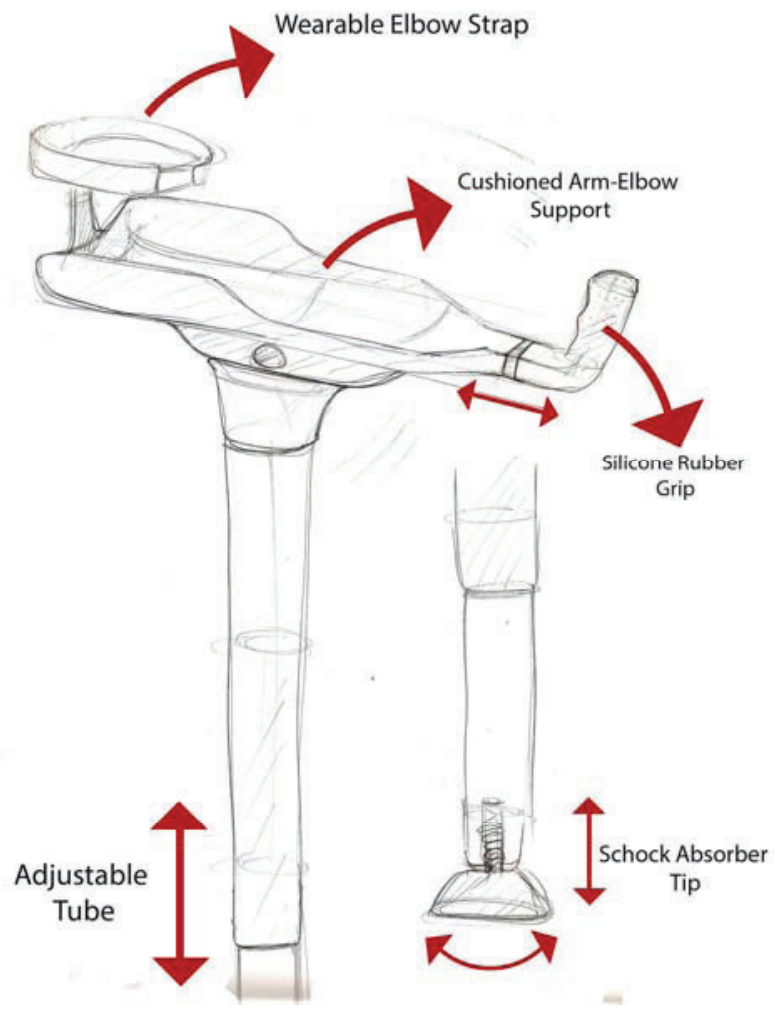

Fig. 6. New Crutch Design Details \& Specifications

\section{CONCLUSION}

Temporary crutch users are patients who do not have physical possibility to use crutches because of the leisured muscle condition. The existing crutches cause some medical problems, which our product specifications aim to solve with applications of new product design process. Therefore, to avoid the medical problems after using crutches, our proposed product ensures distribution of the body weight levelly and body-raise-aid for sitting/standing easily.

Our product specifications conducted with research for walking aid as a medical device design, which offers advantages not only to market, but also to the academics to develop the product with both perspectives. The practicebased system is concreted from the user perspective and medical expert perspective with a user test. The problems of the existing crutches can be solved with body-raised aid, skid-proof, and storage opportunity with three economic scenarios. The crutches would be cheaper than the competitor even it is innovative, because we believe that the medical products should be accessible to every level of income society and it has short-term usage. The general demand of people is to use better, safer products of the medical industry.

The draft design of the proposed new walking aid addresses some of the needs expressed by permanent crutch users. Its cushioned and replaceable arm-elbow support design gives added support and comfort. Also, it provides body-raise aid and stair ascent to the user. The adjustable and replaceable grip assists a good and comfortable grip in different angles. The adjustable and wearable elbow strap and skid-proof replaceable tips ensure a safe use. The draft design bases on the requirements from the research.

However, the proposed design improvements that discussed above need to be implemented and tested with a prototype. There are potential benefits in this study through the further refinements for the permanent crutch users.

The further study can be on technology and material selection through production techniques of walking aids. Another topic can be walking aids for another target such as children, elder people or patients with different symptoms. Therefore the materials allow long-term usage. The use of proposed, however, walking aids should be tested for longterm users after detailed prototype.

\section{REFERENCES}

[1] B. Motyl and S. Filippi, "Integration of Creativity Enhancement Tools in Medical Device Design Process", Procedia Engineering, vol. 69, pp. 1316-1325, 2014.

[2] T. Hagedorn, I. Grosse and S. Krishnamurty, "A concept ideation framework for medical device design", Journal of Biomedical Informatics, vol. 55, pp. 218-230, 2015.

[3] B. Jerrard, M. Trueman and R. Newport, Managing new product innovation. London: Taylor \& Francis, 2003. [18]B. Jerrard, M. Trueman and R. Newport, Managing new product innovation. London: Taylor \& Francis, 2003.

[4] J. Alves, M. Marques, I. Saur and P. Marques, "Creativity and Innovation through Multidisciplinary and Multisectoral 


\section{Proceedings of PICMET '16: Technology Management for Social Innovation}

Cooperation", Creativity and Innovation Management, vol. 16, no. 1, pp. 27-34, 2007.

[5] "World Medical Association Declaration of Helsinki Ethical Principles for Medical Research Involving Human Subjects", Bulletin of the World Health Organization, vol. 79, no. 4, pp. 373- 4, 2001.

[6] S. Ghulam, S. Shah and I. Robinson, "Benefits of and barriers to involving users in medical device technology development and evaluation", International Journal of Technology Assessment in Health Care, vol. 23, no. 01, 2007.

[7] J. Cunningham, B. Dolan, D. Kelly and C. Young, "Medical Device Sectoral Overview", 2016. [Online]. Available: http://galwaydashboard.ie/publications/medical-sector.pdf. [Accessed: 13- Feb- 2016].

[8] R. Mullis and R. Dent, "Crutch length: Effect on energy cost and activity intensity in non[ndash ]weight-bearing ambulation", Archives of Physical Medicine and Rehabilitation, vol. 81, no. 5, pp. 569-572, 2000.

[9] A. Segura, "Biomechanical Evaluation of Crutch Design Variations", The Penn State McNair Journal, vol. 11, pp. 55-70, 2004.

[10] J. Hall and A. Clarke, "An Evaluation of Crutches", Physiotherapy, vol. 77, no. 3, pp. 156-160, 1991.

[11] G. Donin and P. Kneppo, "Medical Device Procurement Tracking System: Concept and Methods", in 6th European Conference of the International Federation for Medical and Biological Engineering, 1st ed., I. Lacković and D. Vasic, Ed. Switzerland: Springer International Publishing, 2015, pp. 629-632.

[12] R. Adedoyin, A. Opayinka and Z. Oladokun, "Energy Expenditure of Stair Climbing with Elbow and Axillary Crutches", Physiotherapy, vol. 88, no. 1, pp. 47-51, 2002.

[13] S. Sherif, S. Hasan, G. Arnold, R. Abboud and W. Wang, "Analysis of hand pressure in different crutch lengths and upper-limb movements during crutched walking", International Journal of Industrial Ergonomics, vol. 53, pp. 59-66, 2016.

[14] D. Shortell, J. Kucer, L. Neeley and M. LeBlanc, "The design of a compliant composite crutch", Journal of Rehabilitation Research and Development, vol. 38, no. 1, pp. 23-32, 2001.

[15] "Health expenditure, total (\% of GDP) | Data | Table", Data.worldbank.org, 2016. [Online]. Available: http://data.worldbank.org/indicator/SH.XPD.TOTL.ZS. [Accessed: 10Feb- 2016].

[16] Health at a Glance 2011: OECD Indicators. Paris: OECD Publications Centre, 2011. http://doi.org/10.1016/S0031-9406(05)60528-7

[17] D. Garde, "Analysts: Device market growth will outpace pharma by 2018",FierceMedicalDevices, 2016. [Online]. Available: http://www.fiercemedicaldevices.com/story/analysts-device-market- growth-will-outpace-pharma-2018/2012-10-03. [Accessed: 10- Mar2016].

[18] U. Topacan, A. Basoglu and T. Daim, "Exploring the Adoption of Technology Driven Services in the Healthcare Industry", International Journal of Information Systems in the Service Sector, vol. 2, no. 1, pp. 71-93, 2010.

[19] "Medical Device Markets in the World to 2018 - Market Size, Trends, and Forecasts",PRNewswire, 2014. [Online]. Available: http://www.prnewswire.com/newsreleases/medical-device-markets-inthe-world-to-2018---market-size-trends-and-forecasts-

267415491.html. [Accessed: 9 January 2015]. Also in J. Cunningham, B. Dolan, D. Kelly and C. Young, "Medical Device Sectoral Overview", 2016.2 [Online]. Available: http://galwaydashboard.ie/publications/medical-sector.pdf. [Accessed: 13- Feb-2016].

[20] C. Llewellyn, D. Podpolny and C. Zerbi, "Capturing the new 'value' segment in medical devices", McKinsey \& Company, 2015. [Online]. Available: http://www.mckinsey.com/industries/pharmaceuticals-andmedical-products/our-insights/capturing-the-new-value-segment-inmedical-devices. [Accessed: 13- Mar- 2016].

[21] "Development of Medical Device Policies", World Health Organization, p. 8, 2011.

[22] H. Kaye, T. Kang and M. LaPlante, Mobility device use in the United States. Washington, D.C.: National Institute on Disability and Rehabilitation Research, U.S. Dept. of Education, 2000.

[23] "Crutches: iWALKFree Hands Free Crutch", iWALK Free, 2016. [Online]. Available: http://www.iwalk-free.com/. [Accessed: 03- Jan2016].

[24] Ergobaum: 6TH Generation Adult Ergonomic Crutches, 2016. [Online]. Available: http://www.ergoactives.com/products/ergobaum. [Accessed: 13- Jan- 2016].

[25] "S_UPPORT - Efficient Plastic Crutch | Tuvie", Tuvie.com, 2016. [Online]. Available: http://www.tuvie.com/s_upport-efficient-plasticcrutch/. [Accessed: 13- Dec- 2015].

[26] "Hurricane Crutch", Hurricanecrutch.com, 2016. [Online]. Available: http://www.hurricanecrutch.com/. [Accessed: 03- Jan- 2016].

[27] "Freedom Leg | You can't do this with crutches.", Freedomlegbrace.com, 2016. [Online]. Available: http://www.freedomlegbrace.com/. [Accessed: 13- Feb- 2016].

[28] X. Crutches, "X-crutch is the best Crutches in the market, high-tech and modern",Wheelchair88 Ltd, 2016. [Online]. Available: https://www.wheelchair88.com/product/x-crutch/. [Accessed: 10- Dec2015].

[29] "Crutches by smartCRUTCH | Crutches for comfort and good looks", Smartcrutch.com, 2016. [Online]. Available: http://www.smartcrutch.com/. [Accessed: 10- Dec- 2015]. 